Schiller als Historiker 


\section{Schiller als Historiker}

Herausgegeben von Otto Dann,

Norbert Oellers und

Ernst Osterkamp

Verlag J. B. Metzler

Stuttgart · Weimar 
Die Deutsche Bibliothek - CIP-Einheitsaufnahme

Schiller als Historiker / hrsg. von Otto Dann ...

- Stuttgart ; Weimar : Metzler, 1995

ISBN 978-3-476-01333-0

NE: Dann, Otto [Hrsg.]

ISBN 978-3-476-01333-0

ISBN 978-3-476-03619-3 (eBook)

DOI 10.1007/978-3-476-03619-3

Dieses Werk einschließlich aller seiner Teile ist urheberrechtlich geschützt. Jede Verwertung außerhalb der engen Grenzen des Urheberrechtsgesetzes ist ohne Zustimmung des Verlages unzulässig und strafbar. Das gilt insbesondere für Vervielfältigungen, Übersetzungen, Mikroverfilmungen und die

Einspeicherung und Verarbeitung in elektronischen Systemen.

(C) 1995 Springer-Verlag GmbH Deutschland

Ursprünglich erschienen bei J. B. Metzlersche Verlagsbuchhundlung und Carl Ernst Poeschel Verlag GmbH in Stuttgart 1995 


\section{Inhalt}

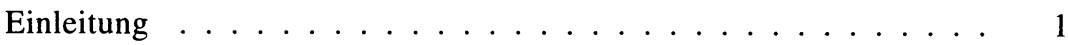

I.

ULRICH MUHLACK:

Schillers Konzept der Universalgeschichte zwischen

Aufklärung und Historismus . . . . . . . . . . . . . . 5

MANFRED RIEDEL:

Geschichte und Gegenwart. Europa in Schillers Konzept

der Universalgeschichte . . . . . . . . . . . . . . . . . . . 29

Helmut KoopmanN:

Das Rad der Geschichte. Schiller und die Überwindung

der aufgeklärten Geschichtsphilosophie . . . . . . . . . . . . 59

WERNER FRICK:

Der >Maler der Menschheit $<$. Philosophische und poetische

Konstruktionen der Gattungsgeschichte bei Schiller. . . . . . . . . . 77

OTTO DANN:

Schiller, der Historiker und die Quellen . . . . . . . . . . . . . . 109

WALTRAud Hagen:

Schillers Geschichtsschreibung aus der Sicht editorischer

Erläuterungsarbeit . . . . . . . . . . . . . 127

II.

ERNST SCHULIN:

Schillers Interesse an Aufstandsgeschichte . . . . . . . . . . . 137

DIETER BORCHMEYER:

Goethes und Schillers Sicht der niederländischen >Revolution< . . . . 149

ERNST OSTERKAMP:

Die Seele des historischen Subjekts. Historische Portraitkunst in Schillers Geschichte des Abfalls der Vereinigten Niederlande von der Spanischen Regierung . . . . . . . . . . . . . . . . . . . . 157 
VI Inhalt

Karl Pestallozzi:

Ferdinand II. in Schillers Geschichte des Dreißigjährigen Kriegs.

Die Rechtfertigung eines Üblen . . . . . . . . . . . . . . . . . . . . 179

Klaus Weimar:

Der Effekt Geschichte . . . . . . . . . . . . . . . . . 191

NORBERT OELLERS:

Poetische Fiktion als Geschichte. Die Funktion erfundener Figuren

in Geschichtsdramen Schillers . . . . . . . . . . . . . . . . 205

BEATRIX LANGNER:

Der Name der Blume. Schillers Trauerspiel Die Braut

von Messina als Dramaturgie der geschichtlichen Vernunft . . . . . . 219

III.

Peter Hanns Reill:

Anthropology, Nature and History in the Late Enlightenment.

The Case of Friedrich Schiller . . . . . . . . . . . . . . . . . . 243

WILHELM SCHMIDT-BIGGEMANN:

Geschichtsentwurf und Erziehungskonzept . . . . . . . . . . . 267

RUdolf MaLTER ( $\dagger$ ):

Schiller und Kant . . . . . . . . . . . . . . . . . . . . . 281

REGINE OTTO:

Schiller und Herder als Geschichtsschreiber.

Annäherungen und Differenzen . . . . . . . . . . . . . . . . 293

MichaEL GotTLOB: Friedrich Schiller und Johannes Müller . . . . . . . 309

Personen-Register . . . . . . . . . . . . . 335 